\title{
A Cross-Talk between the Erythrocyte L-Arginine/ADMA/Nitric Oxide Metabolic Pathway and the Endothelial Function in Subjects with Type 2 Diabetes Mellitus
}

\author{
Damian Gajecki ${ }^{1}{ }^{\circledR}$, Jakub Gawryś ${ }^{1}$, Jerzy Wiśniewski ${ }^{2}$, Paulina Fortuna ${ }^{3}{ }^{\circledR}$, Ewa Szahidewicz-Krupska ${ }^{1}$ \\ and Adrian Doroszko ${ }^{1, * \mathbb{D}}$ \\ 1 Department of Internal Medicine, Hypertension and Clinical Oncology, Wroclaw Medical University, \\ 50-556 Wroclaw, Poland; damian.gajecki@umed.wroc.pl (D.G.); jakub.gawrys@umed.wroc.pl (J.G.); \\ ewa.szahidewicz-krupska@umed.wroc.pl (E.S.-K.) \\ 2 Central Laboratory of Instrumental Analysis, Wrocław University of Science and Technology, \\ Wybrzeże Wyspiańskiego 27, 50-370 Wrocław, Poland; jerzy.wisniewski@pwr.edu.pl \\ 3 Department of Medical Biochemistry, Wroclaw Medical University, 50-368 Wroclaw, Poland; \\ paulina.fortuna@umed.wroc.pl \\ * Correspondence: adrian.doroszko@umed.wroc.pl; Tel.: +48-71-736-4000
}

Citation: Gajecki, D.; Gawryś, J.; Wiśniewski, J.; Fortuna, P.; Szahidewicz-Krupska, E.; Doroszko, A. A Cross-Talk between the Erythrocyte L-Arginine/ADMA/ Nitric Oxide Metabolic Pathway and the Endothelial Function in Subjects with Type 2 Diabetes Mellitus.

Nutrients 2021, 13, 2306.

https://doi.org/10.3390/ nu13072306

\section{Academic Editors:}

Barbara Zubelewicz-Szkodzińska and Bartosz Hudzik

Received: 31 May 2021

Accepted: 2 July 2021

Published: 4 July 2021

Publisher's Note: MDPI stays neutral with regard to jurisdictional claims in published maps and institutional affiliations.

Copyright: (c) 2021 by the authors. Licensee MDPI, Basel, Switzerland. This article is an open access article distributed under the terms and conditions of the Creative Commons Attribution (CC BY) license (https:/ / creativecommons.org/licenses/by/ $4.0 /)$.

\begin{abstract}
Background: Type-2-diabetes-mellitus (DM) is one the most important cardiovascularrisk-factors. Among many molecules regulating vascular tone, nitric oxide appears to be the most pivotal. Although micro- and macrovascular-abnormalities are extensively studied, the alterations in the nitric-oxide-metabolic-pathway require further investigations. Additionally, the role of erythrocytes in the vascular tone regulation has not been extensively explored. The aim of this study was to evaluate the endothelial-function and the nitric-oxide-metabolic-pathway in erythrocytes and plasma of diabetic individuals. (2) Methods: A total of 80 subjects were enrolled in this cross-sectional study, including 35 patients with DM and 45 healthy individuals. The endothelial-function was evaluated in response to different stimuli. (3) Results: In the DM group, decreased Arginine and citrulline concentrations in the plasma compartment with reduced Arginine/ADMA and ADMA/DMA-ratios were observed. Preserved nitric-oxide-metabolism in erythrocytes with reduced citrulline level and significantly higher NO-bioavailability were noted. Significant endothelial dysfunction in DM individuals was proved in response to the heat-stimulus. (4) Conclusions: DM patients at an early stage of disease show significant differences in the nitric-oxide-metabolic-pathway, which are more pronounced in the plasma compartment. Erythrocytes constitute a buffer with a higher nitric-oxidebioavailability, less affected by the DM-related deviations. Patients at an early-stage of DM reveal endothelial-dysfunction, which could be diagnosed earlier using the laser-Doppler-flowmetry.
\end{abstract}

Keywords: erythrocyte; nitric oxide; ADMA; type 2 diabetes mellitus; endothelial dysfunction

\section{Introduction}

Type 2 diabetes mellitus (DM) is one of the most important health emergencies in the 21st century. The population suffering from DM is estimated for 463 million worldwide and is rapidly growing. Predictions say that the number may reach 578 million by 2030, and 700 million by 2045 [1].

$\mathrm{DM}$ is associated with higher relative risk of cardiovascular disorders (CVD) which is estimated between 1.6 and 2.6 and slightly higher in women [2]. Cardiovascular disease in DM patients occurs approximately 15 years earlier than in healthy subjects. It is the main cause of mortality in this group which is different based on sex-dependence. CVD mortality in men with diabetes increases 1-3 times compared to diabetes-free individuals, while the same coefficient estimated in women varies from 2 to 5 times [3]. It is not clear what plays the major role in inducing the differences, but the most important factor seems to be the attenuation of estrogens protective influence against cardiovascular complications 
in DM women. It was proved that DM impairs endothelial response in women to a greater extent than among males [4]. DM diminishes antiproliferative effects of estrogen on the vascular smooth muscle cells by modifying expression, activity, and balance between the estrogen receptors (ER): $E R \alpha$ and $E R \beta$. Domination of $E R \beta$ over $E R \alpha$ activity results in increased inflammatory profile, excessive reactive oxygen species (ROS) formation, and aggravated atherosclerotic plaque formation [5]. In that way, estrogens increase the nitric oxide (NO) bioavailability reducing NO inactivation and additionally may directly increase NO generation [6]. Furthermore, diabetic females are characterized by worse cardiovascular profile, including higher average $\mathrm{HbA1c}$, LDL cholesterol, and BMI levels [4]. Catalan et al. proved that, despite the fact that men more often present carotid plaques in general, in a subgroup of newly diagnosed diabetic women, carotid atherosclerosis was more prevalent [7].

Cardiovascular risk in DM patients is highly dependent on endothelial dysfunction as well as micro- and macrovascular complications coexisting in DM. Among numerous factors, nitric oxide (NO) bioavailability and its metabolic pathway abnormalities seem to be the most crucial. Asymmetric dimethylarginine (ADMA) is a pivotal element leading to the NO synthesis disturbances by competitive inhibiting the nitric oxide synthase (NOS). Significant evidence indicates that not only ADMA concentration per se decides on endothelial function but also the decreased Arginine level and the Arginine/ADMA ratio seems to be additional and potentially more sensitive markers of endothelial dysfunction. The Arginine/ADMA ratio as an indicator of reduced global bioavailability of Arginine and NO production was postulated to be an independent CVD risk factor and to correspond with the severity of hypertension, congestive heart failure, and atherosclerosis $[8,9]$.

Up to date, most of the studies have focused on the NO metabolism abnormalities being seen in the plasma compartment of diabetic subjects. Hardly any of them aims to evaluate the erythrocytes' role in this process. As the red blood cells (RBC) remain in constant contact with the endothelium and enable nitric oxide transport into distant hypoxic areas, their role in regulating the nitric oxide bioavailability might be underestimated. For many years erythrocytes have been considered to just eliminate the $\mathrm{NO}$, which easily reacts with hemoglobin. However, recent studies pointed out that erythrocytes contain NOS and are able to produce NO. Subsequently they release it into the vasculature, regulating the blood flow in distal hypoxic regions [10]. It demonstrates that the conventional theory needs to be verified and the specific role of erythrocytes in the nitric oxide metabolism and its influence on endothelial dysfunction requires detailed evaluation.

Hence, the main goal of this study was to evaluate the nitric oxide metabolism abnormalities in plasma and erythrocytes of diabetic subjects with a close assessment of endothelial function using different tools. Additionally, it was intended to define which of the nitric oxide metabolites reflects better endothelial dysfunction at the early stages of diabetes mellitus.

\section{Materials and Methods}

\subsection{Ethical Approval}

All experiments were conducted and approved in accordance with the guidelines of the Bioethics Committee at the Wroclaw Medical University (KB-155/2019) from 28 February 2019 and adhered to the principles of the Declaration of Helsinki (Seventh Revision, 64th World Medical Association meeting, Fortaleza, 2013). All of the individuals agreed to participate in the study by signing a written informed consent.

\subsection{Patients}

A total of 100 patients were investigated in the study. The inclusion criteria comprised diabetes mellitus diagnosed according to the American and Polish Diabetes Associations criteria, treated with oral metformin at age of 35-80 years. Subjects with the presence of diabetic complications, including microangiopathy, macrovascular diseases, past history of stroke, or myocardial infarction, as well as taking anticoagulant or antiplatelet treatment, 
were excluded from this study. In order to exclude the potential variables affecting the differences between groups, we excluded subjects with concomitant hypertension. Finally, a total of 80 consecutive subjects met properly the inclusion and exclusion criteria and were enrolled to the study, including 35 patients with diabetes mellitus (female: 12 , male: 23 ) and 45 healthy individuals qualified to the control group, respectively.

The control group was recruited from outpatient clinics in pursuance of demographic characteristics (age, sex, region), meeting the inclusion and exclusion criteria properly. All of them had previously undergone the screening for the presence of the glucose metabolism alterations, including diabetes, impaired fasting glycemia, impaired glucose tolerance, and insulin resistance. Subjects with any of these disturbances were excluded from the control group. All of the participants underwent a standard detailed physical examination (Scheme 1).

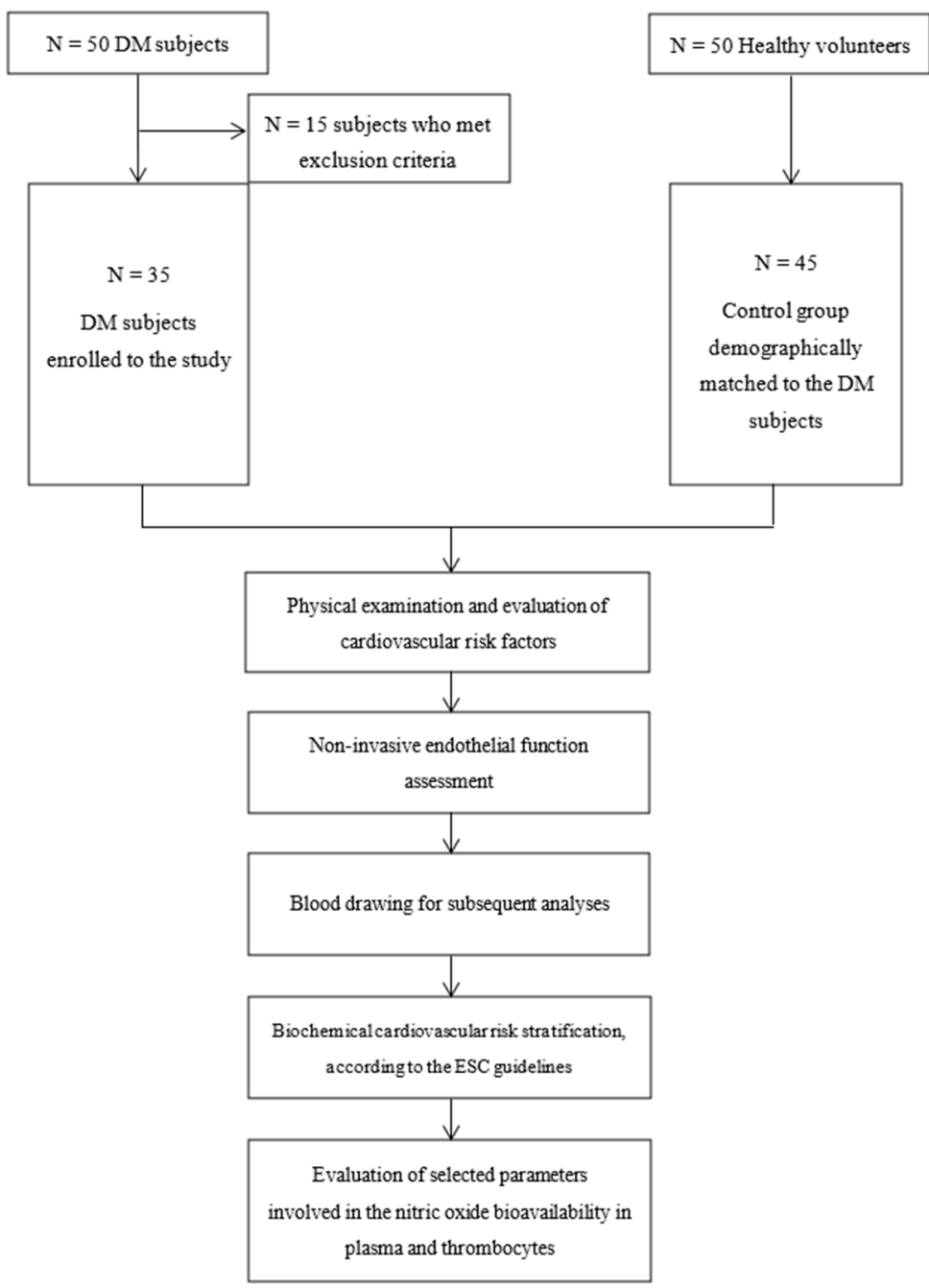

Scheme 1. A flow chart presenting the study protocol.

\subsection{Blood Sample Collection}

Forty-four milliliters of peripheral blood was collected using the Sarstedt S-Monovette ${ }^{\circledR}$ system (Sarstedt AG \& Co., Nümbrecht, Germany). The sample (1.6 mg EDTA/mL blood) tubes within $30 \mathrm{~min}$ after the collection, were centrifuged at $1000 \times \mathrm{g}$ for $15 \mathrm{~min}$ at $4{ }^{\circ} \mathrm{C}$ and stored at $-80^{\circ} \mathrm{C}$ until further analysis. 


\subsection{Erythrocytes Preparation}

The erythrocytes were removed from the plasma within the $10 \mathrm{~min}$ following blood drowning. Erythrocytes samples were thawed on ice. Subsequently, a $10 \mu \mathrm{L}$ of internal standards solution and a $1200 \mu \mathrm{L}$ of cold extraction solution containing methanol, acetonitrile, and water (5:3:2) were added and vortexed (for $15 \mathrm{~min}, 1200 \mathrm{rpm}$ at $4{ }^{\circ} \mathrm{C}$ ). Samples were centrifuged (for $15 \mathrm{~min}, 22,000 \mathrm{rpm}$ at $4{ }^{\circ} \mathrm{C}$ ) and the supernatants were transferred into new microtubes. Samples were then dried at $55^{\circ} \mathrm{C}$ and afterwards dissolved in $100 \mu \mathrm{L}$ of water and vortexed (for $5 \mathrm{~min}, 1200 \mathrm{rpm}$ at $25^{\circ} \mathrm{C}$ ). Subsequently, $50 \mu \mathrm{L}$ of borate buffer $\left(0.025 \mathrm{M} \mathrm{Na}_{2} \mathrm{~B}_{4} \mathrm{O}_{7} \times 10 \mathrm{H}_{2} \mathrm{O}, 1.77 \mathrm{mM} \mathrm{NaOH}, \mathrm{pH}=9.2\right), 400 \mu \mathrm{L}$ of acetonitrile, and $10 \mu \mathrm{L}$ of $10 \%$ benzoyl chloride $(\mathrm{BCl})$ in acetonitrile were added and vortexed again (for $10 \mathrm{~min}$, $1200 \mathrm{rpm}$, at $25^{\circ} \mathrm{C}$ ). After derivatization samples were dried at $55{ }^{\circ} \mathrm{C}$ using the SpeedVac evaporator. Dried samples were reconstituted in $50 \mu \mathrm{L}$ of $3 \%$ of methanol in water and centrifuged (for $10 \mathrm{~min}, 15,000 \mathrm{rpm}$, at $4{ }^{\circ} \mathrm{C}$ ). Clear supernatant was transferred into chromatographic polypropylene vial with attached $200 \mu \mathrm{L}$ insert.

\subsection{Plasma Preparation}

Plasma concentrations of metabolites involved in nitric oxide (NO) synthesis were measured according to method described by Fleszar et al. [11]. Briefly, a $100 \mu \mathrm{L}$ of plasma, $50 \mu \mathrm{L}$ of borate buffer, $10 \mu \mathrm{L}$ of internal standard solution (100 $\mu \mathrm{M}$ D7-Arginine, $20 \mu \mathrm{M}$ D7ADMA, $25 \mu \mathrm{M}$ D6-DMA, $100 \mu \mathrm{M}$ D6-ornithine, and $50 \mu \mathrm{M}$ D4-citrulline) were transferred into the $2 \mathrm{~mL}$ polypropylene tubes and mixed (for $1 \mathrm{~min}, 1200 \mathrm{rpm}$, at $25^{\circ} \mathrm{C}$ ). Then, $400 \mu \mathrm{L}$ of acetonitrile and $10 \mu \mathrm{L}$ of $10 \% \mathrm{BCl}$ in acetonitrile were added and mixed (for $10 \mathrm{~min}, 1200 \mathrm{rpm}$, at $25^{\circ} \mathrm{C}$ ). Subsequently, samples were centrifuged (for $7 \mathrm{~min}$, at $4{ }^{\circ} \mathrm{C}$, $22,000 \mathrm{RCF}$ ) and $100 \mu \mathrm{L}$ of clear supernatant was diluted four times with water, transferred to chromatographic glass vials, and analyzed.

\subsection{Plasma and Erythrocytes Samples Analysis}

The LC-MS/MS analysis was performed using the Acquity UPLC system (Waters, Milford, MA, USA) equipped with cooled autosampler. The sample temperature in an autosampler was $6^{\circ} \mathrm{C}$ and the injection volume was $2 \mu \mathrm{L}$. The Waters BEH Shield C18 column $(1.7 \mu \mathrm{m}, 2.1 \times 10 \mathrm{~mm})$ was thermostatted in a column oven at $60^{\circ} \mathrm{C}$. The flow rate was $0.350 \mathrm{~mL} / \mathrm{min}$, and a total run time was $8 \mathrm{~min}$. Eluents: A: water with $0.1 \%$ formic acid (FA), B: methanol with $0.1 \%$ FA. The following gradient was used: $0.0 \mathrm{~min}-3 \% \mathrm{~B}$, $2.5 \mathrm{~min}-14 \% \mathrm{~B}, 4.6 \mathrm{~min}-60 \% \mathrm{~B}, 4.8 \mathrm{~min}-90 \% \mathrm{~B}, 6.1 \mathrm{~min}-3 \% \mathrm{~B}$.

MS analysis was performed using the SYNAPT G2 Si mass spectrometer (Waters, Milford, MA, USA) equipped with electrospray ionization source (ESI) in a positive ionization mode. The spray voltage, source temperature and the de-solvation temperature were set at $0.5 \mathrm{kV}, 140{ }^{\circ} \mathrm{C}$, and $450{ }^{\circ} \mathrm{C}$, respectively. Data acquisition was performed using the MassLynx software (Waters) for the following ions (m/z): 150.0919, 156.1295, 237.1239, 243.1339, 263.1090, 267.1382, 279.1457, 286.1897, 307.1770, and 314.2209 for DMA, D6-DMA, ornithine, D6-ornithine, citrulline, D4-cytrulline, Arginine, D7-Arginine, ADMA, symmetric dimethylarginine (SDMA), and D7-ADMA, respectively. Standard calibration curves were prepared using the following concentration ranges: 3 to $150 \mu \mathrm{M}$ for ornithine, 5 to $250 \mu \mathrm{M}$ for Arginine, 0.05 to $2.5 \mu \mathrm{M}$ for ADMA and SDMA, 1 to $50 \mu \mathrm{M}$ for citrulline, and 0.14 to $7 \mu \mathrm{M}$ for DMA.

\subsection{Laser Doppler}

All the individuals underwent the laser Doppler flowmetry (LDF) measurements using the Perimed PeriFlux System 5000, Sweden, with a PeriFlux heating unit, performed strictly according to the manufacturer's instructions. The protocol was adapted from our previous study [12]. First, all the individuals were advised to rest for $15 \mathrm{~min}$ in horizontal position in a quiet laboratory at the room temperature $22^{\circ} \mathrm{C}$.

Afterward, their forearm was fixed by a vacuum pillow and the laser probe was placed on a skin, where no superficial veins were visible. The baseline flow and values were 
obtained within the first $10 \mathrm{~min}$ with a probe heated to $33^{\circ} \mathrm{C}$. It was subsequently heated to $43^{\circ} \mathrm{C}$ by the PeriFlux heating unit for the next $30 \mathrm{~min}$ of protocol. According to the previous studies [13-16], there are at least two independent mechanisms that are involved in the skin microvascular vasodilatation in response to local heating. First-a peak observed in laser Doppler flowmetry is caused by the fast-responding vasodilator axon reflex activated by heat-sensitive receptors on afferent nerves mediated by antidromic release of a vasodilatory neurotransmitters (calcitonin gene-related peptide (CGRP), substance P) [17]. After initial brisk increase, the plateau phase is observed, which is followed (after 10-20 min) by slowly responding vasodilator system based on nitric oxide production during prolonged local heating. In order to evaluate the change in the cutaneous blood flow, the maximum heating index (MHI) was counted. It is the ratio between areas under the curve of $10 \mathrm{~min}$ blood flow during maximum heating (late NO-dependent phase) to $10 \mathrm{~min}$ baseline flow (before heating). Using the MHI better reflects nitric-oxide dependent endothelial function, reducing the overlap influence of autonomic system.

\subsection{EndoPAT}

The profile of endothelial function was assessed using the EndoPAT 2000 device (Itamar Medical, Caesarea, Israel). The EndoPAT detects plethysmographic pressure changes in the fingertips, caused by the arterial pulse, where special sensors are placed and translates it to a peripheral arterial tone (PAT). After $6 \mathrm{~min}$ of basal register, the occlusion by sphygmomanometer cuff inflated $40 \mathrm{mmHg}$ over systolic pressure was made. Occlusion measurement was done with additional 5 min of post occlusion measurement (hyperaemic period). The PAT values obtained from contralateral limb serve as a control to exclude the individual systemic changes in blood flow. The achieved data were calculated using a computerized automated algorithm provided with the device. The results were compared using the reactive hyperaemia index (RHI) and its logarithm (lnRHI), which corresponded with the endothelium-mediated changes in vascular tone after occlusion and reflected the arterial endothelial function. Additionally, the augmentation index (AI) was assessed by analyzing the two pressure peaks signals from ascending aorta generated during the cardiac cycle. The first peak was derived from the pulse wave generated by the left ventricle, where the second was the reflection from arterial walls which superimpose to the first ventricular wave. AI is defined by the difference in these pressures, expressed as a percentage of the measured pulse pressure [18]. Its value depends on the vascular stiffness and aorta elasticity. Since it was shown that the augmentation index is heart rate dependent, a more reliable indicator is the augmentation index normalized for a heart rate of $75 \mathrm{bpm}$ (AI-75) [19]. The whole protocol was conducted in pursuance of the manufacturer's instructions. According to the Bonetti et al. study, the RHI cut-off value was set at RHI < 1,67 referring endothelial dysfunction [20]. All experiments were performed in an air-conditioned, quiet room with a constant air temperature of $20^{\circ} \mathrm{C}$.

\subsection{Statistical Analysis}

The data are presented as the mean \pm SD. The differences between two continuous parameters were assessed using a Mann-Whitney U-test or a Student's $t$-test, following the Shapiro-Wilk test and Levene's test as appropriate. Additionally, Spearman's rank correlation coefficient was performed. All calculations were made with Statsoft ${ }^{\circledR}$ Statistica 13.3 software, Krakow, Poland and Graph Pad PRISM ${ }^{\circledR}$ 8.4 San Diego, CA, USA.

\section{Results}

\subsection{Baseline Characteristics}

The study diabetic subjects and healthy controls were matched with respect to the age and sex distribution. There were, however, significant differences in the waist to hip ratio (WHR), weight, body mass index, lipid and glucose metabolism (Table 1). Additionally, higher levels of high-sensitive CRP and uric acid with decreased magnesium and sodium 
concentration were noted in the diabetic subjects. As compared to healthy individuals, patients suffering from DM had significantly higher HOMA-IR and lower QUICKI indexes.

Table 1. Demographic and biochemical characteristics between studied groups including cardiovascular risk stratification parameters. Results are presented as mean $\pm \mathrm{SD}$.

\begin{tabular}{|c|c|c|c|}
\hline Parameter & $\begin{array}{l}\text { Diabetes Group } n=35 \\
\quad(\text { Mean } \pm \text { SD })\end{array}$ & $\begin{array}{l}\text { Control Group } n=45 \\
(\text { Mean } \pm \text { SD })\end{array}$ & $p$ Value \\
\hline Age (year) & $59.80 \pm 9.00$ & $55.42 \pm 10.75$ & NS \\
\hline Women (\%) & $12(34 \%)$ & $19(42 \%)$ & NS \\
\hline Weight (kg) & $88.37 \pm 14.49$ & $78.16 \pm 14.43$ & $<0.05$ \\
\hline WHR & $0.96 \pm 0.08$ & $0.91 \pm 0.12$ & $<0.05$ \\
\hline $\operatorname{BMI}\left(\mathrm{kg} / \mathrm{m}^{2}\right)$ & $30.25 \pm 4.07$ & $25.80 \pm 3.81$ & $<0.05$ \\
\hline $\mathrm{WBC}(\mathrm{k} / \mu \mathrm{L})$ & $7.12 \pm 2.06$ & $6.17 \pm 1.46$ & NS \\
\hline $\operatorname{RBC}(\mathrm{mln} / \mu \mathrm{L})$ & $4.71 \pm 0.46$ & $4.85 \pm 0.58$ & NS \\
\hline Hemoglobin $(\mathrm{g} / \mathrm{dL})$ & $14.30 \pm 1.24$ & $14.58 \pm 1.47$ & NS \\
\hline Hematocrit $(\%)$ & $42.04 \pm 3.53$ & $43.35 \pm 4.68$ & NS \\
\hline MCV (fL) & $89.50 \pm 4.33$ & $89.48 \pm 3.82$ & NS \\
\hline $\mathrm{MCH}(\mathrm{pg})$ & $30.47 \pm 1.87$ & $30.12 \pm 1.41$ & NS \\
\hline $\mathrm{MCHC}(\mathrm{g} / \mathrm{dL})$ & $33.99 \pm 1.03$ & $33.68 \pm 1.13$ & NS \\
\hline Platelets $(\mathrm{k} / \mu \mathrm{L})$ & $253.27 \pm 55.92$ & $244.33 \pm 55.69$ & NS \\
\hline Glucose (mg/dL) & $116 \pm 39.11$ & $93.30 \pm 13.47$ & $<0.05$ \\
\hline $\mathrm{HbA1}$ c $(\%)$ & $6.14 \pm 0.57$ & $5.60 \pm 0.30$ & $<0.05$ \\
\hline Insulin $(\mathrm{uU} / \mathrm{mL})$ & $9.17 \pm 5.38$ & $6.65 \pm 3.49$ & $<0.05$ \\
\hline Total cholesterol (mg/dL) & $194.00 \pm 49.90$ & $214.38 \pm 46.73$ & NS \\
\hline $\mathrm{LDL}(\mathrm{mg} / \mathrm{dL})$ & $113.14 \pm 42.24$ & $130.57 \pm 37.74$ & NS \\
\hline HDL $(\mathrm{mg} / \mathrm{dL})$ & $49.83 \pm 11.70$ & $56.98 \pm 13.76$ & $<0.05$ \\
\hline Triglycerydes $(\mathrm{mg} / \mathrm{dL})$ & $169.14 \pm 108.98$ & $134.26 \pm 69.21$ & NS \\
\hline Urea $(\mathrm{mg} / \mathrm{dL})$ & $34.12 \pm 6.59$ & $33.03 \pm 8.25$ & NS \\
\hline Creatinine $(\mathrm{mg} / \mathrm{dL})$ & $0.92 \pm 0.15$ & $0.96 \pm 0.17$ & NS \\
\hline eGFR (mL/min $/ 1.73 \mathrm{~m}(2))$ & $83.94 \pm 14.49$ & $79.26 \pm 10.93$ & NS \\
\hline Uric acid $(\mathrm{mg} / \mathrm{dL})$ & $6.26 \pm 1.68$ & $5.44 \pm 1.39$ & $<0.05$ \\
\hline Sodium (mmol/L) & $139.41 \pm 1.78$ & $140.36 \pm 2.42$ & $<0.05$ \\
\hline Potassium (mmol/L) & $4.31 \pm 0.28$ & $4.22 \pm 0.35$ & NS \\
\hline Magnesium (mg/dL) & $1.93 \pm 0.23$ & $2.12 \pm 0.16$ & $<0.05$ \\
\hline Calcium (mmol/L) & $9.70 \pm 0.37$ & $9.58 \pm 0.38$ & NS \\
\hline hsCRP (mg/L) & $2.43 \pm 2.42$ & $1.94 \pm 4.67$ & $<0.05$ \\
\hline $\mathrm{TSH}(\mathrm{ulU} / \mathrm{mL})$ & $1.66 \pm 0.95$ & $1.50 \pm 0.67$ & NS \\
\hline Alat $(\mathrm{U} / \mathrm{L})$ & $27.53 \pm 10.97$ & $27.18 \pm 12.63$ & NS \\
\hline hsTroponin I (pg/mL) & $2.31 \pm 2.56$ & $1.32 \pm 1.53$ & NS \\
\hline $\mathrm{BNP}(\mathrm{pg} / \mathrm{mL})$ & $29.16 \pm 38.05$ & $17.68 \pm 15.28$ & NS \\
\hline HOMA-IR & $2.65 \pm 1.56$ & $1.58 \pm 0.82$ & $<0.05$ \\
\hline HOMA beta & $87.64 \pm 119.41$ & $90.17 \pm 49.21$ & NS \\
\hline QUICKI & $0.34 \pm 0.03$ & $0.36 \pm 0.03$ & $<0.05$ \\
\hline
\end{tabular}

Abbreviations: NS: result statistically non-significant; BMI: body mass index; WHR: waist-hip ratio; WBC: white blood cells; RBC: red blood cells; MCV: mean (red blood) cell volume; MCH: mean corpuscular hemoglobin; MCHC: mean corpuscular hemoglobin concentration; PDW: platelet distribution width; eGFR: estimated glomerular filtration rate; HDL: high-density lipoprotein; LDL: low-density lipoprotein; hsCRP: high-sensitivity C-reactive protein; TSH: thyroid-stimulating hormone; BNP: brain natriuretic peptide.

\subsection{Assessment of Endothelial Function}

Assessment of endothelial function by EndoPAT 2000 indicated a significantly higher augmentation index (AI) and the AI normalized for a heart rate of 75 beats $/ \mathrm{min}$ in diabetic patients. As compared to healthy individuals, diabetics had a decreased vascular response observed in the laser Doppler flowmetry, as reflected by decreased maximum hyperaemia index (MHI). The endothelial function assessment is shown in Table 2 and Figure 1. 
Table 2. Assessment of endothelial function by EndoPAT 2000 and the Laser Doppler Flowmetry.

\begin{tabular}{cccc}
\hline Parameter & $\begin{array}{c}\text { Diabetes } \\
\text { (Mean } \pm \text { SD) }\end{array}$ & $\begin{array}{c}\text { Control } \\
\text { (Mean } \pm \text { SD) }\end{array}$ & $p$ Value \\
\hline RHI & $2.19 \pm 0.62$ & $2.28 \pm 0.59$ & NS \\
AI $(\%)$ & $32.97 \pm 22.50$ & $17.76 \pm 19.00$ & $<0.05$ \\
AI-75 (\%) & $25.86 \pm 21.18$ & $10.45 \pm 20.15$ & $<0.05$ \\
MHI & $9.17 \pm 4.82$ & $13.04 \pm 7.44$ & $<0.05$ \\
\hline
\end{tabular}

Abbreviations: NS: result statistically non-significant; RHI: reactive hyperaemia index (EndoPAT 2000), AI: augmentation index (EndoPAT 2000), AI-75 (\%): augmentation index normalized for a heart rate of 75 beats/min (EndoPAT 2000), MHI: maximum hyperaemia index (Laser Doppler Flowmetry).

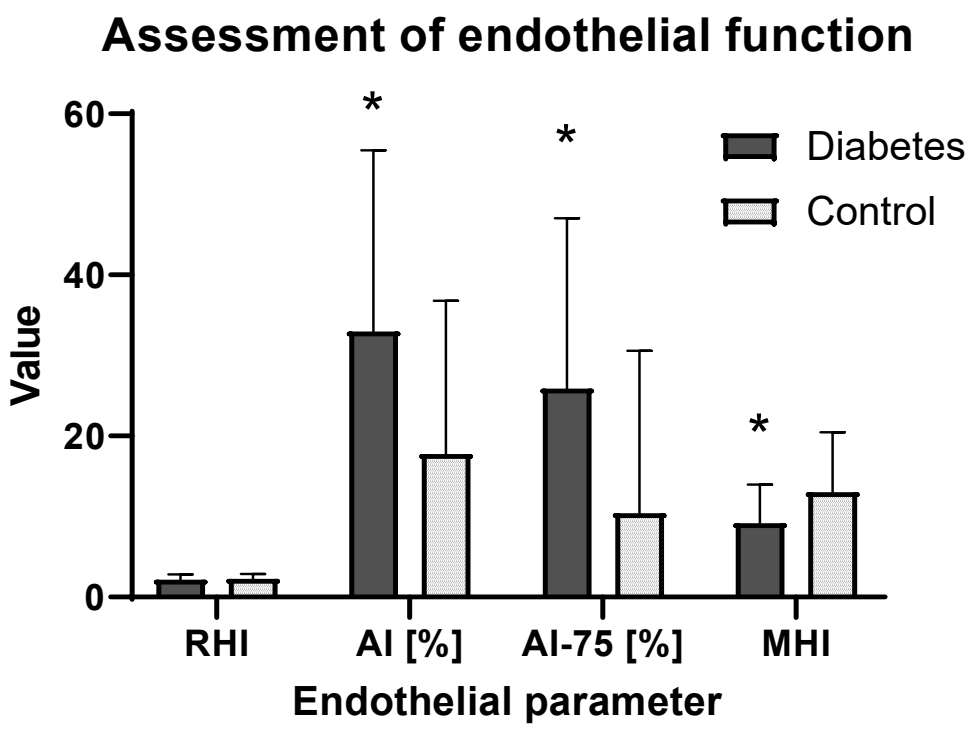

Figure 1. Assessment of endothelial function by EndoPAT 2000 and Laser Doppler Flowmetry. Abbreviations: RHI: reactive hyperaemia index (EndoPAT 2000); AI (\%): augmentation index (EndoPAT 2000), AI-75 (\%): augmentation index normalized for a heart rate of 75 beats $/ \mathrm{min}$ (EndoPAT 2000), MHI: maximum hyperaemia index (Laser Doppler Flowmetry). Correlation of endothelial function with $\mathrm{NO}$ and biochemical metabolites in DM patients. ${ }^{*}-p<0.05$ vs. control.

\subsection{Parameters of the Nitric Oxide Bioavailability in Erythrocytes and Plasma}

Three of the six evaluated metabolites of the nitric oxide pathway were found to be significantly different in the plasma compartment (Arginine, DMA, citrulline). One was found to be altered in the erythrocytes (citrulline), when compared to the control group. The citrulline level was decreased in both compartments among DM patients, which was more noticeable in the erythrocytes. Simultaneously, the Arginine level was reduced in plasma, with no differences in the erythrocyte levels between groups. On the contrary, the dimethylamine (DMA) concentration was increased in plasma which was consecutively not observed in red blood cells (RBCs). All of the alterated nitric oxide metabolites were found at higher concentrations in plasma in both groups.

In order to define the involvement of particular pathways in the alterations of the nitric oxide biotransformation the product to substrate ratios both, in the plasma and erythrocyte compartment in particular reactions were assessed. The study revealed significantly increased ornithine/Arginine and decreased ADMA/DMA ratio in the plasma of DM subjects. Additionally, reduced Arginine/ADMA ratio was noted in plasma with preserved proportion in erythrocytes. By comparing these ratios, higher NO bioavailability in the RBC of diabetic subjects was also identified. Futhermore, Arginine and citrulline compartmental concentration ratio were proved to be statistically different between the groups (Table 3 and Figures 2-4). 
ADMA concentration

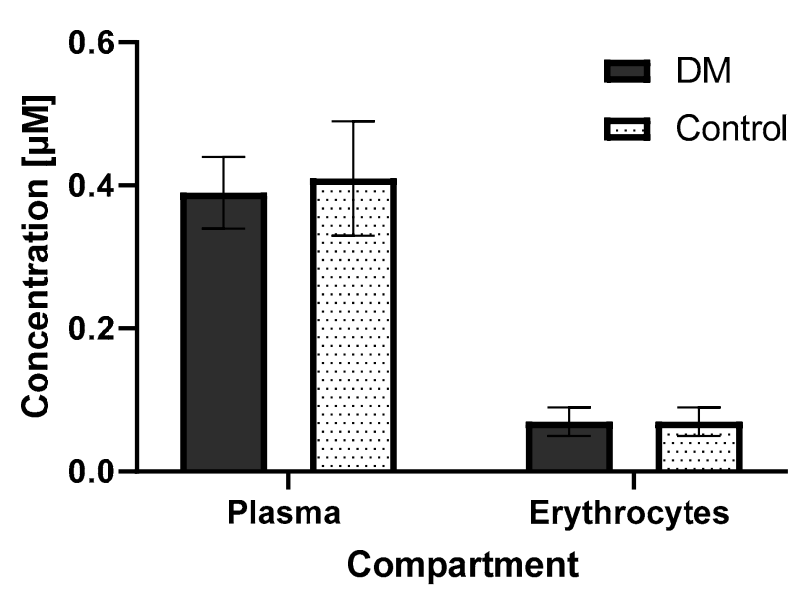

(a)

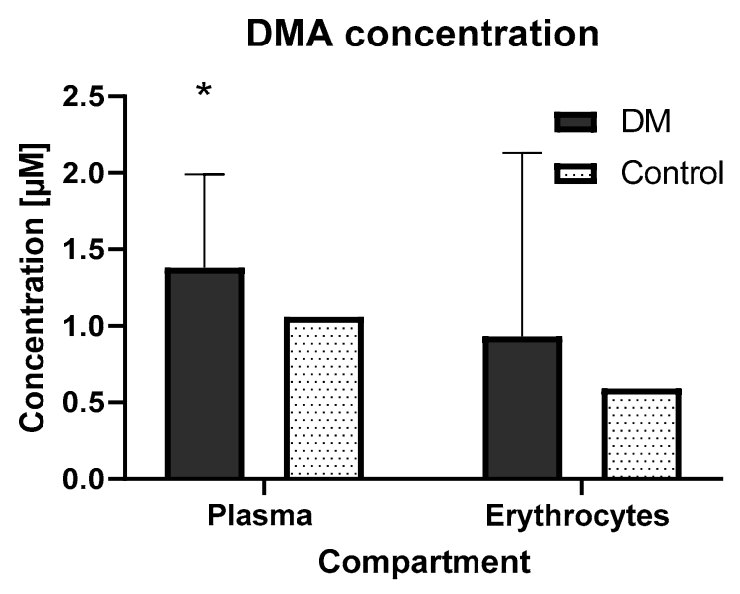

(c)

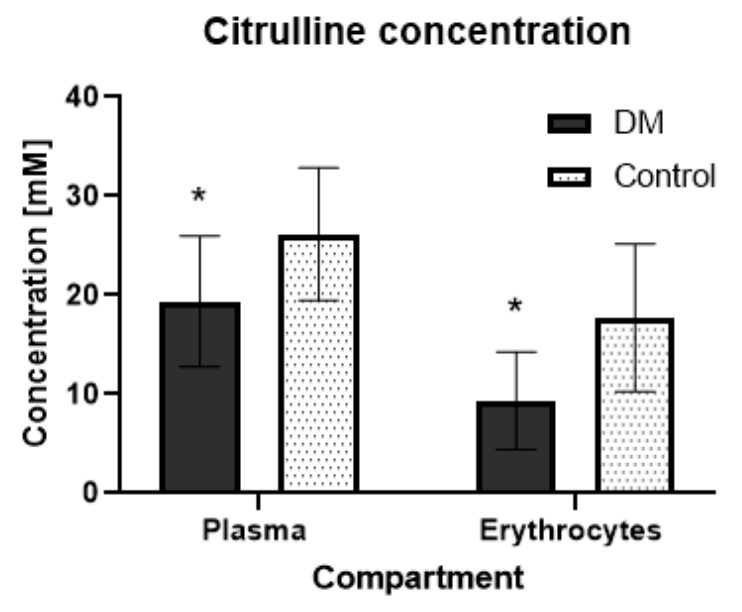

(e)
Arginine concentration

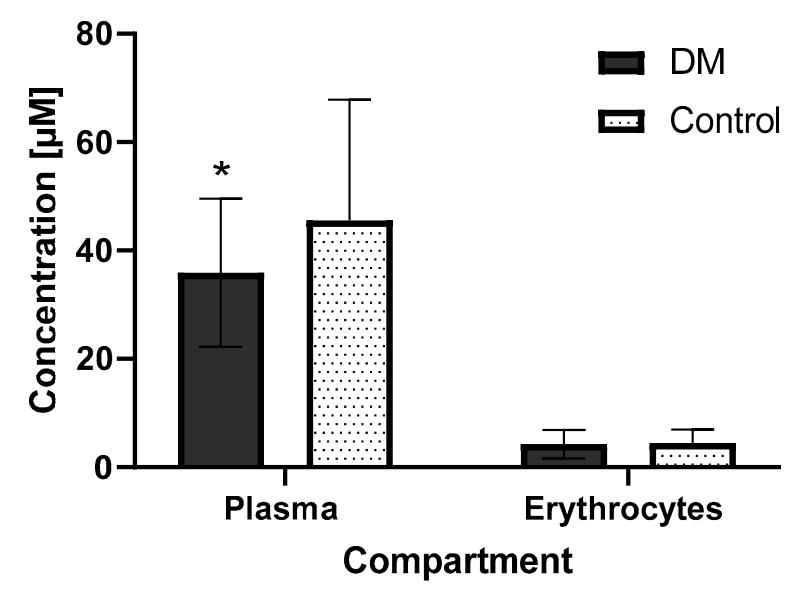

(b)

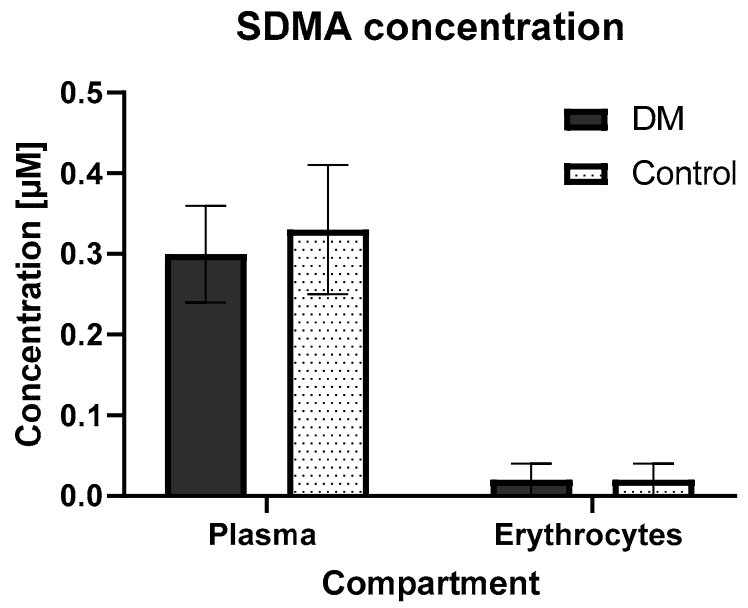

(d)

\section{Ornitine concentration}

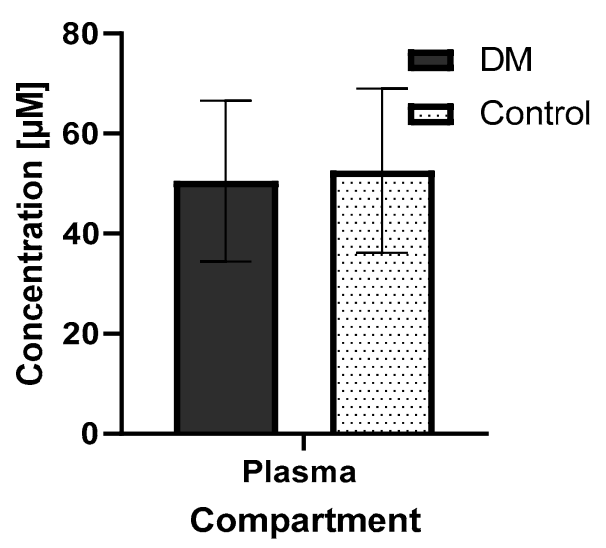

(f)

Figure 2. (a-f) Nitric oxide metabolites concentration in different compartments. ${ }^{*}-p<0.05$ vs. control. 


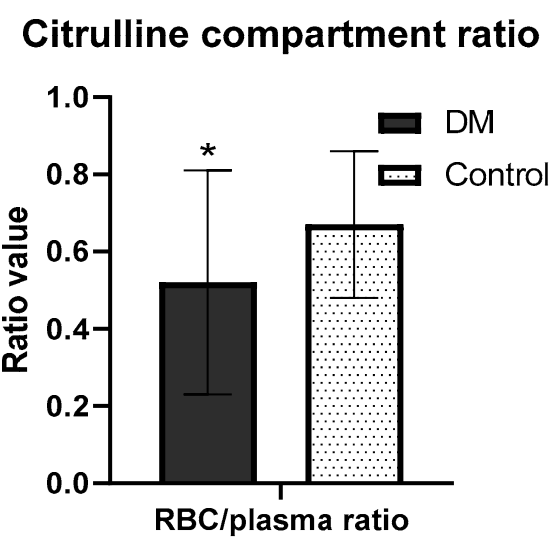

(a)

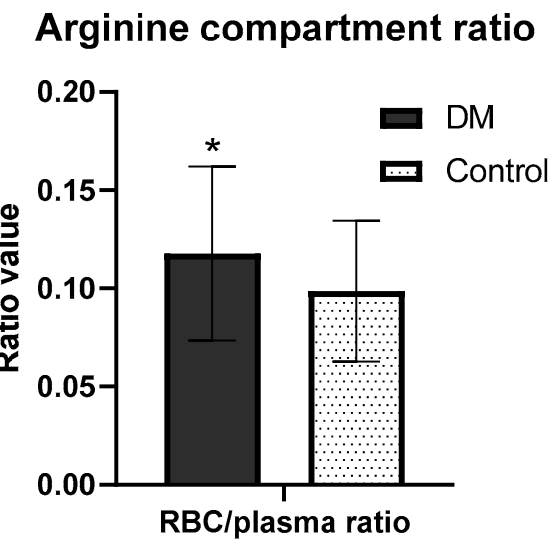

(b)

Figure 3. (a,b) Citrulline and Arginine compartment ratios. ${ }^{*}-p<0.05$ vs. control.

\section{NO bioavailability ratio}

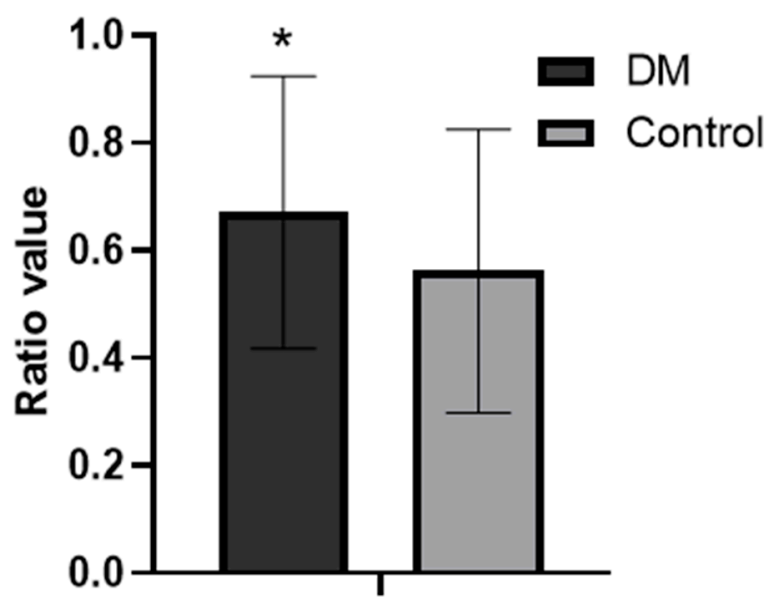

NO erytrocyte/NO plasma bioavailability

Figure 4. Nitric oxide (NO) bioavailability ratio. ${ }^{*}-p<0.05$ vs. control.

Table 3. The Nitric oxide pathway metabolites ratios.

\begin{tabular}{|c|c|c|c|c|c|c|c|c|c|c|c|}
\hline $\begin{array}{l}\text { Plasma } \\
\text { Ratios }\end{array}$ & $\begin{array}{c}\text { DM } \\
\text { Group } \\
\text { (Mean } \pm \\
\text { SD) }\end{array}$ & $\begin{array}{c}\text { Control } \\
\text { Group } \\
\text { (Mean } \pm \\
\text { SD) }\end{array}$ & $p$ Value & RBC Ratios & $\begin{array}{c}\text { DM } \\
\text { Group } \\
\text { (Mean } \pm \\
\text { SD) }\end{array}$ & $\begin{array}{c}\text { Control } \\
\text { Group } \\
\text { (Mean } \pm \\
\text { SD) }\end{array}$ & $p$ Value & $\begin{array}{c}\text { Plasma/RBC } \\
\text { Ratios }\end{array}$ & $\begin{array}{c}\text { DM } \\
\text { Group } \\
\text { (Mean } \pm \\
\text { SD) }\end{array}$ & $\begin{array}{c}\text { Control } \\
\text { Group } \\
\text { (Mean } \pm \\
\text { SD) }\end{array}$ & $p$ Value \\
\hline $\begin{array}{l}\text { Arginine/ } \\
\text { ADMA }\end{array}$ & $\begin{array}{c}94.6 \pm \\
40.3\end{array}$ & $\begin{array}{c}116.5 \pm \\
50.4\end{array}$ & $<0.05$ & $\begin{array}{l}\text { Arginine/ } \\
\text { ADMA }\end{array}$ & $\begin{array}{c}65.03 \pm \\
40.97\end{array}$ & $\begin{array}{c}62.72 \pm \\
34.66\end{array}$ & NS & $\begin{array}{l}\text { Citrulline } \\
\text { RBC/ } \\
\text { Citrulline } \\
\text { plasma }\end{array}$ & $\begin{array}{c}0.52 \pm \\
0.29\end{array}$ & $\begin{array}{c}0.67 \pm \\
0.19\end{array}$ & $<0.05$ \\
\hline ADMA/DMA & $\begin{array}{c}0.37 \pm \\
0.23\end{array}$ & $\begin{array}{c}0.47 \pm \\
0.24\end{array}$ & $<0.05$ & ADMA/DMA & $\begin{array}{c}0.06 \pm \\
0.04\end{array}$ & $\begin{array}{c}0.07 \pm \\
0.07\end{array}$ & NS & $\begin{array}{l}\text { Arginine } \\
\text { RBC/ } \\
\text { Arginine } \\
\text { plasma }\end{array}$ & $\begin{array}{c}0.12 \pm \\
0.04\end{array}$ & $\begin{array}{c}0.10 \pm \\
0.04\end{array}$ & $<0.05$ \\
\hline $\begin{array}{l}\text { Ornitine/ } \\
\text { Arginine }\end{array}$ & $\begin{array}{c}1.69 \pm \\
0.90\end{array}$ & $\begin{array}{c}1.18 \pm \\
0.59\end{array}$ & $<0.05$ & & & & & & & & \\
\hline
\end{tabular}




\subsection{Assessment of the Relationship between Biochemical Results and Endothelial Function}

The analysis of biochemical results and endothelial function revealed a moderate correlation between AI and eGFR and BNP. A similar correlation was found between endothelial function measured using EndoPAT and ADMA concentration, ADMA/Arginine ratio, and NO bioavailability in the RBC compartment with no such dependence in the plasma of DM patients (Figure 5).

\section{Correlation of endothelial function with NO an biochemical metabolites in DM patients}

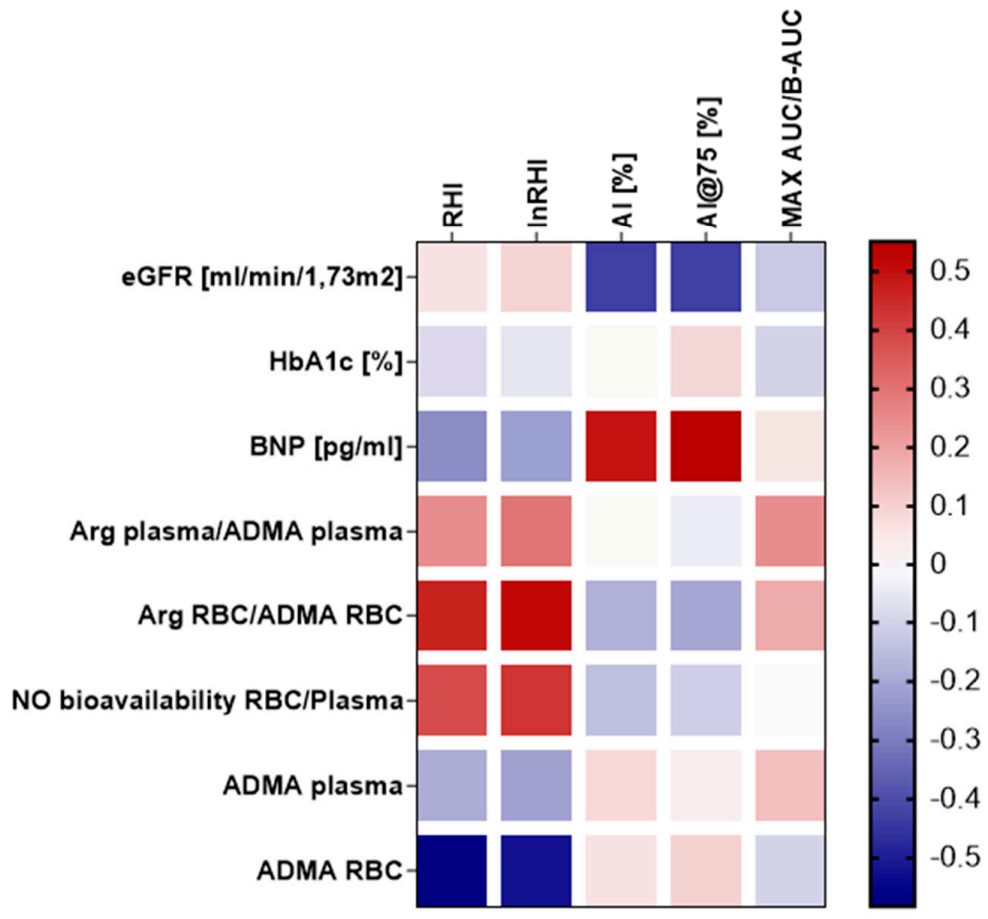

Figure 5. Correlation of endothelial function with NO and biochemical metabolites in DM patients. Abbreviations: RHI: reactive hyperaemia index (EndoPAT 2000); AI (\%): augmentation index (EndoPAT 2000), AI-75 (\%): augmentation index normalized for a heart rate of 75 beats $/ \mathrm{min}$ (EndoPAT 2000), MHI: maximum hyperaemia index (Laser Doppler Flowmetry); RBC: red blood cells; eGFR: estimated glomerular filtration rate; BNP: brain natriuretic peptide; ADMA: Asymmetric dimethylarginine; Arg: L-Arginine.

\section{Discussion}

To our knowledge, this is the first research that evaluates the nitric oxide metabolic pathway both, in erythrocyte and plasma compartments. Furthermore, the erythrocyte nitric oxide metabolism and endothelial dysfunction in diabetic subjects were assessed. Recent findings emphasize the key role of endothelial dysfunction in diabetic patients as the first step leading to the development of vascular complications and organ damage.

Insulin resistance, a hallmark of metabolic syndrome, impairs vascular response and increases cardiovascular risk. Involvement of insulin resistance and endothelial dysfunction in pathological disorders contribute to impairment in the NO-dependent vasodilatation, cellular glucose uptake, enhancement in oxidative stress, and inflammation, leading finally to atherosclerosis. Strong association of insulin and endothelial signaling disturbances contributes inflammation, disrupting the balance between vasodilating-vasoconstrictive endothelial mechanisms as well as between the insulin-dependent PI3-K/Akt-MAPK/ERK pathways [21].

For many years erythrocytes have been considered to be a natural sink for the NO molecules because of hemoglobin abundance which easily scavenge NO. However, recent 
studies give more evidence that erythrocytes' role is far more complex, and they appear to be an important source of NO. In line with the studies that confirmed the activity of NOS in erythrocytes, the research proved the existence of nitric oxide metabolites and enzymatic inhibitors in RBCs. Besides citrulline concentration, no other alterations in the nitric oxide metabolites in erythrocytes of diabetic patients were found. It indicates that erythrocytes remain a buffer which is less affected by the deviations connected with endothelial dysfunction and that the synthesis of nitric oxide in erythrocytes remain unaltered in early diabetic individuals. Nitric oxide bioavailability in different compartments was also compared using the Arginine/asymmetric dimethylarginine ratio, which is a well-established marker of global Arginine bioavailability and the NO production. The analysis revealed its significantly higher values in the RBC which points out, even more distinctly, the importance of erythrocytes in preserving NO production in DM (Figure 6).

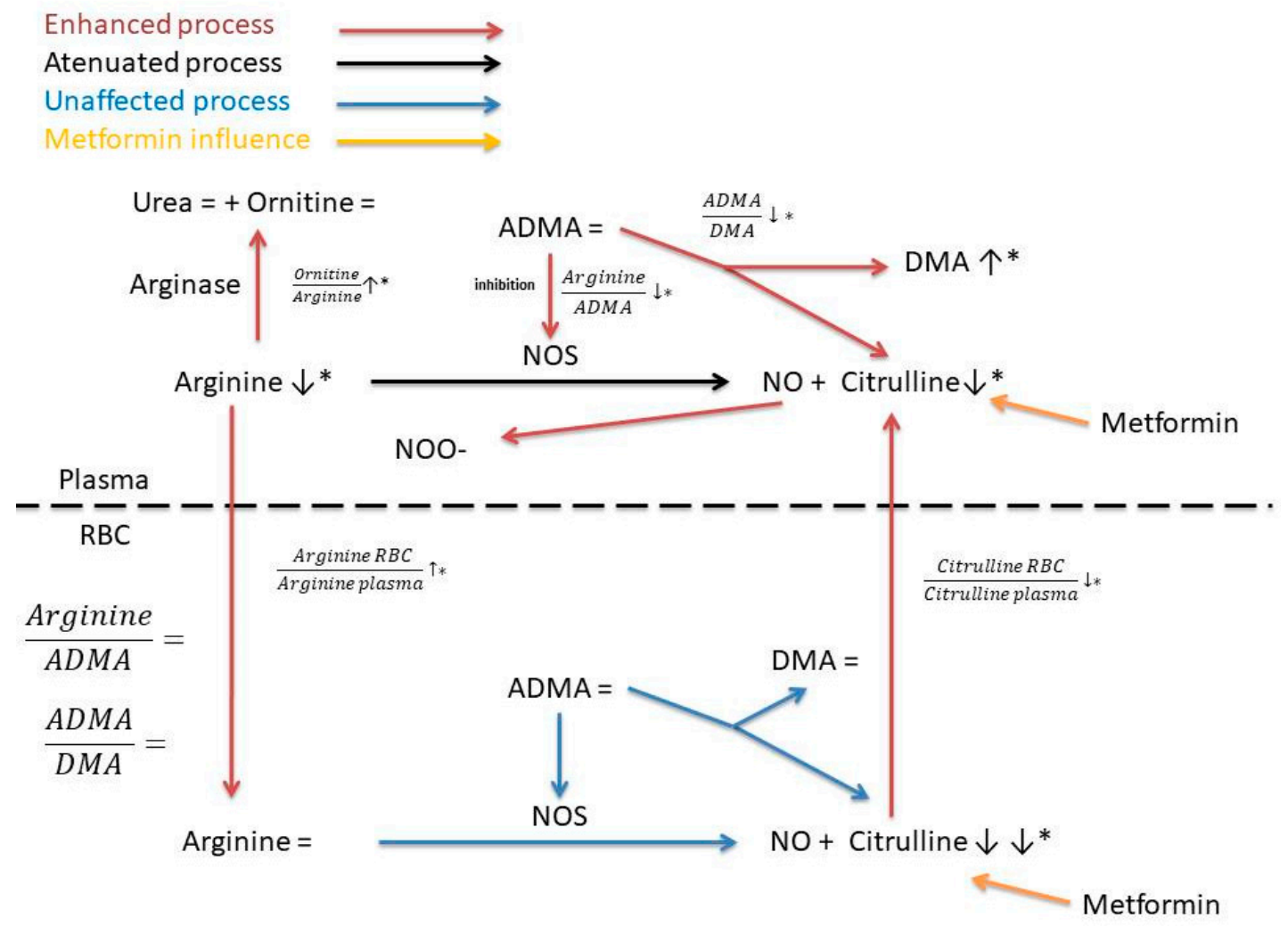

Figure 6. Nitric oxide metabolism alteration in different compartments. Abbreviations: ADMA: asymmetric dimethylarginine; DMA: dimethylamine; NOS: nitric oxide synthase; NO: nitric oxide RBC: erythrocyte SDMA: symmetric dimethylarginine. ${ }^{*}-p<0.05$ vs. control.

Contrary to the RBC compartment, substantial abnormalities in the NO synthesis in the plasma of DM patients were confirmed. First of all, a significantly reduced Arginine concentration was shown. It may be caused by shunting the L-Arginine from the eNOS to the arginase pathway with its enhanced arginase degradation, as an increased ornithine to Arginine ratio in plasma was found $[18,22,23]$. It is noteworthy that the results are in accordance with the studies by Shemyakin et al., proving that the downregulation of arginase improves endothelial function among patients with DM and may become a promising therapeutic target [24].

Additionally, enhanced Arginine transport from plasma to erythrocytes were found as Arginine compartment ratios were significantly different. Increased transport via system $y+$ in human erythrocytes had already been confirmed in different diseases affecting nitric oxide transformation, such as renal failure and chronic heart diseases $[25,26]$. It 
may indicate that the same upregulation of $y+$ transport occurred in the DM group as a compensatory response to maintain the NO production.

Furthermore, low level of Arginine leads to the NOS uncoupling and results in excessive reactive oxygen species (ROS) formation, which also stems from NADPH oxidase (NOX) and mitochondrial complexes reactions [27]. As a result, the NO bioavailability is reduced in different ways-by decreased production because of substrate depletion and increased elimination through reaction with reactive oxygen species.

Moreover, significantly reduced Arginine to ADMA ratio in the DM group was also revealed, pointing at reduced NOS action and a subsequently diminished NO production. As no difference in ADMA concentration per se was found nor an increased DMA level, it collectively points at higher ADMA turnover in DM patients. Current literature is inconclusive in the assessment of dimethylarginine.

Dimethylaminohydrolase (DDAH) activity in diabetics, which is related with ADMA concentration. Numerous studies suggest that the high glucose level accompanied by increased concentration of proinflammatory cytokines, such as tumour necrosis factor (TNF), results in decreased DDAH activity and consequent increased ADMA level [28-32]. Our study cohort was composed of early-stage diabetic patients treated with metformin without the micro- and macrovascular complications. The low $\mathrm{HbA1c}$ levels reflect good glucose control, which may progressively result in preserved DDAH activity. This observation is consistent with the Xiong et al. study, proving the correlation of ADMA level with the macroangiopathy occurrence but not with the disease duration [33]. Additionally, DM patients were treated with metformin, which is a structural analog of ADMA reducing its concentration, possibly in the DDAH-dependent manner [34-37]. Furthermore, metformin reduces the advanced glycation end-products (AGEs) concentration what additionally restores the NO bioavailability [38].

Significantly lower plasma values of the citrulline in DM patients resulting from reduced eNOS activity caused by depletion of Arginine and increased inhibition were also found. Additionally, the use of metformin reduces citrulline levels [39,40]. According to Breier, M. et al. studies, short-term therapy with metformin reduces citrulline concentration by mean of $24 \%$ which is in compliance with results of this study-a $26 \%$ depletion on average of citrulline concentration between groups [39]. The mechanism of metformindependent citrulline reduction is not clear. Some authors seek the mechanism in urea cycle activity changes, inhibition of mitochondrial complex I, increased urinary excretion by kidneys, or decreased gut absorption associated with gastrointestinal side effects of metformin [39,41-43]. Reduced citrulline concentration in the erythrocyte compartment, more pronounced in the DM group was also noted.

In this study, the endothelial function using the two independent methods was also evaluated. First, the vascular response was assessed using the peripheral arterial tonometry with a post-occlusive reactive hyperaemia (PORH) measured as a reactive hyperaemia index (RHI). Second, with the laser Doppler flowmetry (LDF). A diminished endothelial function was found only by using the second method.

The pathophysiology of the vascular relaxation in response to numerous stimuli (heating or occlusion) is different and may explain to some extent, why only local thermal hyperemia (LTH) indicates endothelial dysfunction in the diabetic subjects. The sensory nerves response and endothelium-derived hyperpolarizing factors have been described as the major points affecting both, the initial peak and the following increased blood flow after occlusion. Putative elements affecting PORH include the cytochrome epoxygenase metabolites and the large-conductance calcium-activated potassium channels (BKCa) in the vascular smooth muscle cells and in sensory nerves [44-46]. Hence, compared to other mechanisms regulating vascular response, the role of nitric oxide pathway in the post-occlusion response turned out not to be so crucial $[47,48]$.

On the contrary, in the LDF response to heating stimuli, nitric oxide is responsible for vascular response in approximately 70\% [49]. The first phase is mediated by a local sensory nerve axon reflex and the plateau depends mostly on the NO [45,49]. The maximum 
hyperemia index (MHI) was used to eliminate the neuronal influence. It reflects the nitric oxide-dependent plateau phase and expresses the endothelial function. Applying MHI results in a higher sensitivity and explains the discrepancies between the LTH and PORH outcomes. The results of this research are in line with Faisel and Heier studies, who confirmed endothelial dysfunction in diabetes mellitus type 1 group using LDF with intact vascular reaction in peripheral arterial tonometry $[50,51]$.

The results showed that the augmentation index (AI) in diabetics was statistically higher, strictly corresponding with the increased vascular stiffness and the reduced flexibility of the aorta among diabetic patients Additionally, the AI-75 positively correlated with BNP concentration $(r=0.55)$ and negatively with the eGFR value $(r=-0.43)$. It reflects that arterial stiffness in DM patients appears at the early stage of the disease and induces the organ-mediated complications from the beginning.

The nitric oxide metabolic pathway was also compared by correlating the products concentrations with the endothelial function results. The analysis confirmed that the endothelial function in DM patients correlated with NO bioavailability and NOS activity more in the RBC compartment than in plasma ( $r=0.38$ and $r=0.46)$. Furthermore, similar dependency was found within the erythrocyte ADMA concentration $(r=-0.58)$ (Figure 2). Hence, it may be postulated that erythrocytes play an important role in compensating the endothelial dysfunction occurring in DM. Further studies are needed to evaluate their specific position in the NO metabolism and to define novel therapeutic targets to prevent the DM micro- and macrovascular complications.

\section{Conclusions}

Patients at an early stage of DM revealed endothelial dysfunction, which could be diagnosed earlier using the laser Doppler flowmetry. This group of subjects showed significant differences in the nitric oxide metabolism, which was more pronounced in the plasma compartment. The research proved decreased NOS activity with aggravated ADMA degradation and Arginine depletion. It indicated that erythrocytes remain a buffer less affected by the DM deviations with higher NO bioavailability than in the plasma compartment. Additionally, it was revealed that endothelial dysfunction correlates to a greater extent with abnormalities of nitric oxide pathway noted in RBC than in plasma compartment. The disclosed findings show the importance of the RBC as a NO-buffer. Hence, the RBCs play a key-role in maintenance a healthy vascular status in those with early diabetes mellitus. Additional studies in that field should be performed in order to extend the knowledge regarding the RBC NO-buffer, which may be used in the prevention or treatment of vascular complications in the diabetic group.

\section{Limitations}

Several limitations of this study should be addressed. The first limitation regards the measured molecules. As NO easily reacts with hemoglobin it was not possible to measure it directly and our results are mainly based on by-products which are more stable. Furthermore, different permeability of erythrocyte membrane may affect compartment distribution and study outcomes. The separation process might affect the analytes equilibrium, therefore additional experiments should be conducted to assess the potential significance of that process. In this study, subjects with newly onset of diabetes, without concomitant cardiovascular disorders, were investigated. Hence, the results of this study cannot be simply extrapolated to the whole spectrum of diabetic population.

Author Contributions: Conceptualization, A.D. and D.G.; methodology, A.D., J.W., P.F., and E.S.-K.; software, D.G. and A.D.; validation, D.G., A.D., and J.G.; formal analysis, D.G. and A.D.; investigation, D.G. and J.G.; resources, A.D.; data curation, D.G.; writing-original draft preparation, D.G.; writingreview and editing, A.D.; visualization, D.G.; supervision, A.D.; project administration, J.G. and E.S.-K.; funding acquisition, J.G. and A.D. All authors have read and agreed to the published version of the manuscript. 
Funding: This research was funded by Wrocław Medical University according to the records in Simple system, grant number STM.A210.18.026 and STA210.17.057.

Institutional Review Board Statement: The study was conducted according to the guidelines of the Declaration of Helsinki and approved by the Bioethics Committee at the Wroclaw Medical University (KB-155/2019) from 28 February 2019.

Informed Consent Statement: Informed consent was obtained from all subjects involved in the study.

Data Availability Statement: The original data used to support the findings of this study are available from the corresponding author upon request.

Conflicts of Interest: The authors declare no conflict of interest.

\section{Abbreviations}

\begin{tabular}{|c|c|}
\hline ADMA & asymmetric dimethylarginine \\
\hline AGEs & advanced glycation end-products \\
\hline AI & augmentation index \\
\hline AI-75 [\%] & augmentation index normalized for a heart rate of 75 beats $/ \mathrm{min}$ \\
\hline Arg & L-Arginine \\
\hline $\mathrm{BCl}$ & benzoyl chloride \\
\hline BMI & body mass index \\
\hline BNP & brain natriuretic peptide \\
\hline CVD & cardiovascular disorders \\
\hline DDAH & Dimethylaminohydrolase \\
\hline DM & Diabetes mellitus \\
\hline DMA & dimethylamine \\
\hline eGFR & estimated glomerular filtration rate \\
\hline ER & estrogen receptors \\
\hline ESC & European Society of Cardiology \\
\hline $\mathrm{HbA1c}$ & glycated hemoglobin \\
\hline HDL & high-density lipoprotein \\
\hline hsCRP & high-sensitivity C-reactive protein \\
\hline LDF & laser Doppler flowmetry \\
\hline LDL & low-density lipoprotein \\
\hline $\ln \mathrm{RHI}$ & reactive hyperaemia index logarithm \\
\hline LTH & local thermal hyperemia \\
\hline $\mathrm{MCH}$ & mean corpuscular hemoglobin \\
\hline $\mathrm{MCHC}$ & mean corpuscular hemoglobin concentration \\
\hline $\mathrm{MCV}$ & mean (red blood) cell volume \\
\hline MHI & maximum heating index \\
\hline $\mathrm{NO}$ & nitric oxide \\
\hline NOS & nitric oxide synthase \\
\hline NOX & NADPH oxidase \\
\hline NS & result statistically non-significant \\
\hline PAT & peripheral arterial tone \\
\hline PDW & platelet distribution width \\
\hline PORH & post-occlusive reactive hyperaemia \\
\hline $\mathrm{RBC}$ & red blood cells \\
\hline RHI & reactive hyperemia index \\
\hline ROS & reactive oxygen species \\
\hline SDMA & symmetric dimethylarginine \\
\hline TNF & tumour necrosis factor \\
\hline $\mathrm{TSH}$ & thyroid-stimulating hormone \\
\hline WBC & white blood cells \\
\hline WHR & waist-hip ratio \\
\hline
\end{tabular}




\section{References}

1. International Diabetes Federation. International Diabetes IDF Diabetes Atlas, 9th ed.; International Diabetes Federation: Brussels, Belgium, 2019.

2. Sarwar, N.; Gao, P.; Kondapally Seshasai, S.R.; Gobin, R.; Kaptoge, S.; Di Angelantonio, E.; Ingelsson, E.; Lawlor, D.A.; Selvin, E.; Stampfer, M.; et al. Diabetes mellitus, fasting blood glucose concentration, and risk of vascular disease: A collaborative meta-analysis of 102 prospective studies. Lancet 2010, 375, 2215-2222. [PubMed]

3. Lee, W.; Cheung, A.; Cape, D.; Zinman, B. Impact of Diabetes on Coronary Artery A meta-analysis of prospective studies. Diabetes Care 2000, 23, 962-968. [CrossRef]

4. Ballotari, P.; Ranieri, S.C.; Luberto, F.; Caroli, S.; Greci, M.; Rossi, P.G.; Manicardi, V. Sex Differences in Cardiovascular Mortality in Diabetics and Nondiabetic Subjects: A Population-Based Study (Italy). Int. J. Endocrinol. 2015, 2015, 1-10. [CrossRef] [PubMed]

5. Dantas, A.P.V.; Fortes, Z.B.; de Carvalho, M.H.C. Vascular Disease in Diabetic Women: Why Do They Miss the Female Protection? Exp. Diabetes Res. 2012, 2012, 1-10. [CrossRef]

6. Novensa, L.; Selent, J.; Pastor, M.; Sandberg, K.; Heras, M.; Dantas, A.P. Equine Estrogens Impair Nitric Oxide Production and Endothelial Nitric Oxide Synthase Transcription in Human Endothelial Cells Compared with the Natural 17 $\beta$-Estradiol. Hypertens 2010, 56, 405-411. [CrossRef] [PubMed]

7. Catalan, M.; Herreras, Z.; Pinyol, M.; Sala-Vila, A.; Amor, A.; de Groot, E.; Gilabert, R.; Ros, E.; Ortega, E. Prevalence by sex of preclinical carotid atherosclerosis in newly diagnosed type 2 diabetes. Nutr. Metab. Cardiovasc. Dis. 2015, 25, 742-748. [CrossRef] [PubMed]

8. Yu, E.; Ruíz-Canela, M.; Hu, F.B.; Clish, C.B.; Corella, L.; Salas-Salvadó, J.; Hruby, A.; Fíto, M.; Liang, L.; Toledo, E.; et al. Plasma Arginine/Asymmetric Dimethylarginine Ratio and Incidence of Cardiovascular Events: A Case-Cohort Study. J. Clin. Endocrinol. Metab. 2017, 102, 1879-1888. [CrossRef] [PubMed]

9. Bode-Böger, S.; Scalera, F.; Ignarro, L. The l-arginine paradox: Importance of the l-arginine/asymmetrical dimethylarginine ratio. Pharmacol. Ther. 2007, 114, 295-306. [CrossRef] [PubMed]

10. Cortese-Krott, M.M.; Kelm, M. Endothelial nitric oxide synthase in red blood cells: Key to a new erythrocrine function? Redox Biol. 2014, 2, 251-258. [CrossRef]

11. Fleszar, M.G.; Wiśniewski, J.; Krzystek-Korpacka, M.; Misiak, B.; Frydecka, D.; Piechowicz, J.; Lorenc-Kukuła, K.; Gamian, A. Quantitative Analysis of 1-Arginine, Dimethylated Arginine Derivatives, l-Citrulline, and Dimethylamine in Human Serum Using Liquid Chromatography-Mass Spectrometric Method Mass to charge ratio MRM Multiple reaction monitoring NO Nitric oxide NOS Nitric oxide synthase OPA Ortho-phthaldialdehyde. Chromatographia 2018, 1, 911-921.

12. Doroszko, A.; Szahidewicz-Krupska, E.; Janus, A.; Jakubowski, M.; Turek, A.; Ilnicka, P.; Szuba, A.; Mazur, G.; Derkacz, A. Endothelial dysfunction in young healthy men is associated with aspirin resistance. Vasc. Pharmacol. 2015, 67-69, 30-37. [CrossRef]

13. Kellogg, D.L. In vivo mechanisms of cutaneous vasodilation and vasoconstriction in humans during thermoregulatory challenges. J. Appl. Physiol. 2006, 100, 1709-1718. [CrossRef] [PubMed]

14. Farrell, D.M.; Bishop, V.S. Permissive role for nitric oxide in active thermoregulatory vasodilation in rabbit ear. Am. J. Physiol. Circ. Physiol. 1995, 269, H1613-H1618. [CrossRef]

15. Shibasaki, M.; Wilson, T.E.; Cui, J.; Crandall, C.G. Acetylcholine released from cholinergic nerves contributes to cutaneous vasodilation during heat stress. J. Appl. Physiol. 2002, 93, 1947-1951. [CrossRef]

16. Shastry, S.; Dietz, N.M.; Halliwill, J.R.; Reed, A.S.; Joyner, M.J. Effects of nitric oxide synthase inhibition on cutaneous vasodilation during body heating in humans. J. Appl. Physiol. 1998, 85, 830-834. [CrossRef]

17. Minson, C.T.; Berry, L.T.; Joyner, M.J. Nitric oxide and neurally mediated regulation of skin blood flow during local heating. $J$. Appl. Physiol. 2001, 91, 1619-1626. [CrossRef]

18. Beleznai, T.; Feher, A.; Spielvogel, D.; Lansman, S.L.; Bagi, Z. Arginase 1 contributes to diminished coronary arteriolar dilation in patients with diabetes. Am. J. Physiol. Circ. Physiol. 2011, 300, H777-H783. [CrossRef] [PubMed]

19. Lantelme, P.; Mestre, C.; Lievre, M.; Gressard, A.; Milon, H. Heart rate: An important confounder of pulse wave velocity assessment. Hypertension 2002, 39, 1083-1087. [CrossRef] [PubMed]

20. Bonetti, P.O.; Pumper, G.M.; Higano, S.T.; Holmes, D.R.; Kuvin, J.T.; Lerman, A. Noninvasive identification of patients with early coronary atherosclerosis by assessment of digital reactive hyperemia. J. Am. Coll. Cardiol. 2004, 44, 2137-2141. [CrossRef]

21. Janus, A.; Szahidewicz-Krupska, E.; Mazur, G.; Doroszko, A. Insulin Resistance and Endothelial Dysfunction Constitute a Common Therapeutic Target in Cardiometabolic Disorders. Mediat. Inflamm. 2016, 2016, 1-10. [CrossRef]

22. Hein, T.W.; Omae, T.; Xu, W.; Yoshida, A.; Kuo, L. Role of Arginase in Selective Impairment of Endothelium-Dependent Nitric Oxide Synthase-Mediated Dilation of Retinal Arterioles during Early Diabetes. Investig. Opthalmol. Vis. Sci. 2020, 61, 36. [CrossRef]

23. Kashyap, S.R.; Lara, A.; Zhang, R.; Park, Y.M.; DeFronzo, R.A. Insulin Reduces Plasma Arginase Activity in Type 2 Diabetic Patients. Diabetes Care 2007, 31, 134-139. [CrossRef]

24. Shemyakin, A.; Kövamees, O.; Rafnsson, A.; Böhm, F.; Svenarud, P.; Settergren, M.; Jung, C.; Pernow, J. Arginase Inhibition Improves Endothelial Function in Patients With Coronary Artery Disease and Type 2 Diabetes Mellitus. Circulation 2012, 126, 2943-2950. [CrossRef] [PubMed] 
25. Mendes Ribeiro, A.C.; Hanssen, H.; Kiessling, K.; Roberts, N.B.; Mann, G.E.; Ellory, J.C. Transport of L-arginine and the nitric oxide inhibitor N(G)-monomethyl-L-arginine in human erythrocytes in chronic renal failure. Clin. Sci. 1997, 93, 57-64. [CrossRef]

26. Hanssen, H.; Brunini, T.M.C.; Conway, M.; Banning, A.P.; Roberts, N.B.; Mann, G.E.; Ellory, J.C.; Ribeiro, A.C.M. Increased 1-arginine Transport in Human Erythrocytes in Chronic Heart Failure. Clin. Sci. 1998, 94, 43-48. [CrossRef] [PubMed]

27. Zhou, Z.; Mahdi, A.; Tratsiakovich, Y.; Zahorán, S.; Kövamees, O.; Nordin, F.; Gonzalez, A.E.U.; Alvarsson, M.; Östenson, C.-G.; Andersson, D.C.; et al. Erythrocytes From Patients With Type 2 Diabetes Induce Endothelial Dysfunction Via Arginase I. J. Am. Coll. Cardiol. 2018, 72, 769-780. [CrossRef] [PubMed]

28. Yamagishi, S.-I.; Ueda, S.; Nakamura, K.; Matsui, T.; Okuda, S. Role of Asymmetric Dimethylarginine (ADMA) in Diabetic Vascular Complications. Curr. Pharm. Des. 2008, 14, 2613-2618. [CrossRef] [PubMed]

29. Murphy, R.B.; Tommasi, S.; Lewis, B.C.; Mangoni, A.A. Inhibitors of the Hydrolytic Enzyme Dimethylarginine Dimethylaminohydrolase (DDAH): Discovery, Synthesis and Development. Molecules 2016, 21, 615. [CrossRef]

30. Palm, F.; Onozato, M.L.; Luo, Z.; Wilcox, C.S. Dimethylarginine dimethylaminohydrolase (DDAH): Expression, regulation, and function in the cardiovascular and renal systems. Am. J. Physiol. Circ. Physiol. 2007, 293, H3227-H3245. [CrossRef] [PubMed]

31. Bestermann, W.H. The ADMA-Metformin Hypothesis: Linking the Cardiovascular Consequences of the Metabolic Syndrome and Type 2 Diabetes. Cardiorenal Med. 2011, 1, 211-219. [CrossRef]

32. Wadham, C.; Mangoni, A.A. Dimethylarginine dimethylaminohydrolase regulation: A novel therapeutic target in cardiovascular disease. Expert Opin. Drug Metab. Toxicol. 2009, 5, 303-319. [CrossRef]

33. Xiong, Y.; Lei, M.; Fu, S.; Fu, Y. Effect of diabetic duration on serum concentrations of endogenous inhibitor of nitric oxide synthase in patients and rats with diabetes. Life Sci. 2005, 77, 149-159. [CrossRef]

34. Asagami, T.; Abbasi, F.; Stuelinger, M.; Lamendola, C.; McLaughlin, T.; Cooke, J.; Reaven, G.; Tsao, P. Metformin treatment lowers asymmetric dimethylarginine concentrations in patients with type 2 diabetes. Metabolism 2002, 51, 843-846. [CrossRef]

35. Tsai, C.-M.; Kuo, H.-C.; Hsu, C.-N.; Huang, L.-T.; Tain, Y.-L. Metformin reduces asymmetric dimethylarginine and prevents hypertension in spontaneously hypertensive rats. Transl. Res. 2014, 164, 452-459. [CrossRef]

36. Stühlinger, M.C.; Abbasi, F.; Chu, J.W.; Lamendola, C.; McLaughlin, T.L.; Cooke, J.; Reaven, G.M.; Tsao, P.S. Relationship Between Insulin Resistance and an Endogenous Nitric Oxide Synthase Inhibitor. JAMA 2002, 287, 1420-1426. [CrossRef] [PubMed]

37. Bal, F.; Bekpinar, S.; Unlucerci, Y.; Kiraz, Z.K.; Önder, S.; Uysal, M.; Gurdol, F. Antidiabetic drug metformin is effective on the metabolism of asymmetric dimethylarginine in experimental liver injury. Diabetes Res. Clin. Pract. 2014, 106, 295-302. [CrossRef] [PubMed]

38. Andújar-Plata, P.; Pi-Sunyer, X.; Laferrère, B. Metformin effects revisited. Diabetes Res. Clin. Pract. 2012, 95, 1-9. [CrossRef] [PubMed]

39. Breier, M.; Wahl, S.; Prehn, C.; Ferrari, U.; Sacco, V.; Weise, M.; Grallert, H.; Adamski, J.; Lechner, A. Immediate reduction of serum citrulline but no change of steroid profile after initiation of metformin in individuals with type 2 diabetes. J. Steroid Biochem. Mol. Biol. 2017, 174, 114-119. [CrossRef]

40. Adam, J.; Brandmaier, S.; Leonhardt, J.; Scheerer, M.F.; Mohney, R.P.; Xu, T.; Bi, J.; Rotter, M.; Troll, M.; Chi, S.; et al. Metformin Effect on Nontargeted Metabolite Profiles in Patients With Type 2 Diabetes and in Multiple Murine Tissues. Diabetes 2016, 3, 23. [CrossRef] [PubMed]

41. Owen, M.R.; Doran, E.; Halestrap, A.P. Evidence that metformin exerts its anti-diabetic effects through inhibition of complex 1 of the mitochondrial respiratory chain. Biochem. J. 2000, 348, 607-614. [CrossRef]

42. Irving, B.A.; Carter, R.E.; Soop, M.; Weymiller, A.; Syed, H.; Karakelides, H.; Bhagra, S.; Short, K.; Tatpati, L.; Barazzoni, R.; et al. Effect of Insulin Sensitizer Therapy on Amino Acids and Their Metabolites. Metabolism 2015, 64, 720-728. [CrossRef]

43. Irving, B.A.; Spielmann, G. Does Citrulline Sit at the Nexus of Metformin's Pleotropic Effects on Metabolism and Mediate Its Salutatory Effects in Individuals with Type 2 Diabetes? Diabetes 2016, 65, 3537-3540. [CrossRef]

44. Lorenzo, S.; Minson, C.T. Human cutaneous reactive hyperaemia: Role of BK Ca channels and sensory nerves. J. Physiol. 2007, 585, 295-303. [CrossRef]

45. Roustit, M.; Cracowski, J.-L. Assessment of endothelial and neurovascular function in human skin microcirculation. Trends Pharmacol. Sci. 2013, 34, 373-384. [CrossRef]

46. Cracowski, J.-L.; Gaillard-Bigot, F.; Cracowski, C.; Sors, C.; Roustit, M.; Millet, C. Involvement of cytochrome epoxygenase metabolites in cutaneous postocclusive hyperemia in humans. J. Appl. Physiol. 2013, 114, 245-251. [CrossRef] [PubMed]

47. Wong, B.; Wilkins, B.W.; Holowatz, L.A.; Minson, C.T. Nitric oxide synthase inhibition does not alter the reactive hyperemic response in the cutaneous circulation. J. Appl. Physiol. 2003, 95, 504-510. [CrossRef]

48. Zhao, J.L.; Pergola, P.E.; Roman, L.J.; Kellogg, D.L. Bioactive nitric oxide concentration does not increase during reactive hyperemia in human skin. J. Appl. Physiol. 2004, 96, 628-632. [CrossRef]

49. Brunt, V.E.; Minson, C.T. Cutaneous thermal hyperemia: More than skin deep. J. Appl. Physiol. 2011, 111, 5-7. [CrossRef] [PubMed]

50. Khan, F.; Elhadd, T.A.; Greene, S.A.; Belch, J.J.F. Impaired Skin Microvascular Function in Children, Adolescents, and Young Adults with Type 1 Diabetes. Diabetes Care 2000, 23, 215-220. [CrossRef]

51. Heier, M.; Espeland, C.N.; Brunborg, C.; Seljeflot, I.; Margeirsdottir, H.D.; Hanssen, K.F.; Fugelseth, D.; Dahl-Jørgensen, K. Preserved endothelial function in young adults with type 1 diabetes. PLoS ONE 2018, 13, e0206523. [CrossRef] [PubMed] 